\title{
CASTING LIGHT UPON THE GREAT ENDARKENMENT
}

\author{
DAVID LUMSDEN AND JOSEPH ULATOWSKI
}

\begin{abstract}
While the Enlightenment promoted thinking for oneself independent of religious authority, the 'Endarkenment' (Millgram 2015) concerns deference to a new authority: the specialist, a byperspecializer. Non-specialists need to defer to such authorities as they are unable to understand their reasoning. Millgram describes how humans are capable of being serial hyperspecializers, able to move from one specialism to another. We support the basic thrust of Millgram's position, and seek to articulate how the core idea is deployed in very different ways in relation to extremely different philosophical areas. We attend to the issue of the degree of isolation of different specialists and we urge greater emphasis on parallel hyperspecialization, which describes how different specialisms can be embodied in one person at one time.
\end{abstract}

Keywords: rationality, specialization, interdisciplinarity, philosophical methodology, Elijah Millgram.

\section{Specialization and the Great Endarkenment}

It is a commonplace, in the academy but also at large, that there are specialists for seemingly everything. A notable early form of specialization outside the academy is Henry Ford's automobile 'assembly line' where different workers each perform their own specialist task. Contemporary research scientists, by contrast, have become very narrowly focused in a rather different way, one that relies on a complex network of theoretical knowledge. That narrowness of focus is in stark contrast with scientists of the Enlightenment, such as Newton, who were expected to have a broad knowledge of the science of the time. A quick inspection of recent $\mathrm{PhD}$ topics and titles of articles in contemporary leading scientific journals will show that the work is not going to be read or understood by someone with a passing interest in the area. Specialists are the target audience. 
Of course, experts in specialist fields also have knowledge and skills in other areas, which allows them to navigate the modern world of mobile phone plans, tax returns, social media, car insurance and so forth. But, in those areas, the knowledge and skills are not concentrated in the hands of a few in the same way. A different case is where a single person is a specialist in more than one field, a point to which we shall return.

When we receive opinions and advice from a specialist outside of our area of knowledge, we find that we cannot absorb their detailed explanations. The vocabulary experts employ, even in cases where it echoes an ordinary language term, is generally inaccessible to the non-expert. On occasion, we may not even know which kind of specialist to consult for a particular problem. Suppose that we want to assess the structural integrity of Auckland's Sky Tower and the tower's ability to withstand an 8.5 magnitude earthquake. We do not know whether a geophysicist, a structural engineer, or a geologist would be best suited to evaluate the tower's robustness. Moreover, we may not be in a position to distinguish the genuine expert from the fraud. For that kind of judgment, we must appreciate the nuances of the expert's thinking and justification for making an assertion about the integrity of the Sky Tower's structure.

In The Great Endarkenment (2015), Elijah Millgram works with the theme of specialization and develops some radical views about the nature of knowledge and the human mind, which he links to a new philosophical methodology. We believe his work is extremely fruitful, and we wish to articulate some main themes with our commentary and even at one point to extend the ideas. As Millgram $(2015,22)$ explains, a central feature of the Enlightenment was an emphasis on thinking for oneself, in particular in the way that science can discover new knowledge without needing to defer to religious authority. Throughout the broad sweep of the Enlightenment there were many thinkers, such as Daniel Bernoulli, Leonardo DaVinci, and Leonhard Euler, who didn't focus on just one particular area but were led by their insatiable curiosity into a wide array of scientific problems and mathematical paradoxes. The title of Millgram's volume is a play on the idea that, with extreme specialization, we, in a way, must once more defer to authority, the authority of the specialist, since we cannot be privy to the wisdom of a specialism outside our own area (Millgram 2015,28). Chapters in the volume, seven of which have been revised from earlier published work, address this and related themes. Millgram's volume contains a rich network of intersecting themes supported by a complex array of arguments and, of necessity, we must keep a narrow focus. In what follows, we shall endeavor to draw out that theme of hyperspecialization from across a few chapters, with a particular focus on serial 
hyperspecialization, and develop some reactions to it. We then turn our attention to the sibling notion of parallel hyperspecialization, something scarcely mentioned by Millgram, and wish to make a case for its importance in a way that is complementary to serial specialization.

\section{Hyperspecialization}

In the process of developing his central theme, Millgram introduces the term 'hyperspecialization', which is an extreme form of specialization.

[S]pecialization is far more highly articulated than at any time in previous human history, and because this difference in degree has come to amount to a difference in kind, I'll mark the newly extreme form of division of labor with the label byperspecialization. (Millgram 2015, 2)

In many places, the references to hyperspecialization occur in an academic context and indeed it is a commonplace that disciplines have become subdivided into successively narrower disciplines. Millgram applies the notion of hyperspecialization beyond a narrowly academic setting, though, for example to the expertise associated with an occupation or profession and, as we shall see, more broadly still.

The extreme form of specialization that interests Millgram arises out of the proprietary nature of communication had between experts, people who narrowly focus upon one area or topic and who have cultivated that specialty over a number of years. Modern life forces society to construct some extreme, narrowly focused concepts. ${ }^{1}$ Petroleum engineers communicate well with other petroleum engineers, but such individuals have a difficult time communicating with geologists and geophysicists, despite there being clear connections between their areas of expertise. Even at a more mundane level, we cannot function with just a single set of widely held concepts, for many aspects of life that a person may or may not need to deal with, such as preparing a tax return or engaging with Facebook, require a grasp of the appropriate specialist notions. The point of philosophical interest emerges when one specialist is so tied to their own

${ }^{1}$ Arguments for the replacement of analytic philosophy's current stewardship of the conceptual realm with something more fine-grained and nuanced are found in Ruth Garrett Millikan's views involving unicepts $(2017,42-55)$ and Mark Wilson's conception of the prevailing approach as "dressing every concept in common khaki" $(2006,13)$. An early, and too often overlooked, expositor, of views such as those discussed in Millgram, Millikan, and Wilson is Meir Buzaglo (2002). 
notions and methods that there is mutual incomprehensibility with a specialist in another area, even a closely related area. While one can grasp the gist of the overall thesis, it is a feature of Millgram's volume that the examples and explanations of the nature of hyperspecialization change from context to context, a feature consistent with the overall orientation and methodology employed, as we shall discuss in a moment. The basic idea extends a lot further than we may first suspect. ${ }^{2}$

\section{Serial Hyperspecialization}

While there is no doubt that human beings tend to specialize, or arguably hyperspecialize, in one narrowly conceived area, it is notable that some human beings, with some effort, are able to pass from one area of interest or specialization to another. Millgram discusses this idea in relation to hyperspecialization. He writes:

[People] work their way into any one of an apparently open-ended list of disciplines or professions, and what is more, they are able to switch from one to another -- although because the costs of doing so are high, these migrations do not happen very many times over the course of a life. Thus someone might (real example) start out as a dancer, then work for an architecture firm specializing in theater design, then for an IT department, and subsequently become a vice-president of a bank. (Millgram 2015, 6)

On Millgram's account, this real example marks a particular kind of hyperspecialization: it's serial hyperspecialization. Clearly, the serial hyperspecializer is someone who can move from one specialist domain to another by acquiring new knowledge and skills. Millgram thinks it is a significant characteristic of humans that we are capable of making such transitions, while other species such as bees or ants have fixed specialist roles. It is part of the evolutionary heritage of humanity that we have the capacity to move to a new specialty.

One thing a person needs to acquire in a move to a new specialty is a new vocabulary. Millgram acknowledges that new vocabularies "are not always scientific or academic vocabularies: a while back, I was up on my roof, talking to a roofer, and I literally could not understand what he was

${ }^{2}$ We could cast a sociological eye on the nature of these specialist groups in science and elsewhere: how they are formed, how membership is regulated and so forth. That is not the main driver for Millgram, though, as he is more interested in the way that specialist concepts are shared only narrowly and what it shows about how the minds of the specialists work. 
telling me" (Millgram 2015, 148). This is a rare occasion of intellectual humility in a philosopher's work. Millgram, a Harvard trained philosopher, couldn't understand the vocabulary of a tradesman. Moreover, he admits, the vocabularies are just 'the tip of this iceberg'. "Serial hyperspecializers develop systems of standards, priorities, and guidelines that frame decision and choice within particular disciplines" (Millgram 2015, 148). The example of the roofer brings out the way that this whole approach and way of thinking can apply to choices of a very practical nature, which may involve practical skills.

While this example may make us think of an old school roofer who acts alone, we should remember that participation in a specialism implies the existence of a group of specialists. Membership of a specialist community supports fruitful interactions and common standards and practices. This is part and parcel of the notion of specialization as Millgram understands it. When he focuses on specifically serial hyperspecialization, he focuses on the cognitive and professional journey of a single individual, for he is looking at how one person can migrate from one specialization to another. But, of course, that journey presupposes the existence of distinct communities of specialists, communities that support internal interaction but cannot foster proper communication with members of other communities of specialists. The base level sociological fact is that modern human societies organize themselves into relatively discrete specialist communities. Millgram's thesis of serial hyperspecialization adds to that fact the potential of individual people to navigate their way between those communities.

Serial hyperspecialization is a central theme of Chapter 10: Segmented Agency. The central idea is that the progress of an individual from one specialization to another demonstrates how there is no unified agent over time. The chapter employs an example that transports us from the lot of the academic into the arena of social and political change. A Jewish philosopher in 1930s Germany has been accustomed to making decisions on the basis of some well-established policies: "accepting the advice of his Doktorvarter, not making life choices on the basis of outlandish rumors, and not letting politics impinge on career decisions" (Millgram 2015, 246). Those principles were central to him as an agent. But the increasing anti-Semitic policies of the Nazis turn his whole world upside down. In order to survive and function, he needs to completely abandon those principles that were central to his agency and adopt a whole new way of thinking. For Millgram, this shows that agency is segmented, in that there is no single agent that persists through the transition. This example reinforces the point that hyperspecialization, 
and indeed serial hyperspecialization, are not simply features of the nature of scientific knowledge, in Millgram's view. We need to apply those notions differently in this context.

\section{Millgram's Methodology}

If the thesis of hyperspecialization were true, it would have implications for how philosophers should go about their work. Where philosophers are focusing on the very theme of hyperspecialization, and how it plays out in different contexts, they face the difficulty that they need to delve into different areas of knowledge and activity for which a specialist is required. At least, one would need to proceed in a piecemeal fashion, which is precisely how Millgram describes his approach in this volume. Really one would need a diverse team with different areas of specialist knowledge (see Millgram 2015, 278-9) but, in order to show the new way, it is reasonable for a single author to delve into various topics as best he can. The eclectic structure of the volume thus reflects the themes under discussion. Moreover, the volume is taken to illustrate a certain philosophical methodology. The methodological innovation is referred to relatively briefly in Chapter 1: Introductory Remarks on the Tower of Babel, is taken up in the body of the volume, as discussed below in relation to chapters 6 and 8 , and is returned to, again briefly, in the concluding Chapter 11: Afterword: A Call to Arms. The best test of the approach, though, is the way the method is put into effect in relation to various topics in the different chapters.

One methodological approach Millgram very clearly opposes is the classic technique of analytic philosophy that takes key concepts from ordinary language, such as 'know', 'true' and 'ought' and subjects them to careful analysis. ${ }^{3}$ This relies on the semantics of our ordinary language capturing a folk wisdom that has been refined over the ages (Millgram 2015, 12). This approach will not work in a world in which a serial hyperspecializer needs to readjust the whole basis of her thinking, including the concepts at its core, in adapting to new circumstances. As well as considering the journey of the individual hyperspecializer, we need to consider how a society or group as a whole can shift to a new setting based on different concepts as well as different standards, priorities, and guidelines for action. Therefore, on this approach, there are no eternal truths that a philosopher can discover by conceptual analysis.

We have already emphasized how the central notion of hyperspecialization can be realized differently in different settings. Indeed, it is a consequence of the new methodology, itself

3 One is reminded here of Mark Wilson's $(2006 ; 2017)$ distinction between stewards and custodians of the conceptual realm. 
prompted by the theme of hyperspecialization, that there will be no definitive analysis of the notion of hyperspecialization. The methodology grounded in hyperspecialization tells us not to expect a unitary concept of hyperspecialization. So, when different chapters give us rather different realizations of hyperspecialization, that is precisely what we should expect! Millgram provides some useful guidance about how to conduct philosophical enquiry when he talks of metaphysics as intellectual ergonomics (Millgram 2015, 13). ${ }^{4}$ Metaphysics should be about the design of intellectual devices that make reasoning and inference about the world in which we find ourselves tractable and effective, a cognitive-function analysis. As the practical, scientific, and social settings vary, so will the nature of those intellectual devices.

\section{Applications to Value Theory}

We should look at some particular examples of how the main themes in the volume are developed. Earlier we mentioned that hyperspecialists form groups with internal social coordination, although the innovator will often start out alone. The kind of group we are talking about can vary significantly, though, as becomes clear when we look at the application of the theme of hyperspecialization to morality. Here we need to take a broad view of hyperspecialization, which takes us well beyond groups based on academic specializations. There are four chapters in the volume that relate in some way to value theory, but let us focus initially on Chapter 9: Applied Ethics, Moral Skepticism, and Reasons with Expiration Dates, which considers philosophy's lack of success in answering the fundamental question of moral psychology, "Why be moral?"

Millgram's explanation for that lack of success is that we have been making the mistake of seeking definitive refutations of moral skepticism. ${ }^{5}$ We will do better if we look for temporary reasons, ones that come with expiration dates. That makes sense if we see moral values located in a particular social niche so that, as society changes, so does the morality that governs it.

Moving from one social niche to another with different moral imperatives can be viewed as akin to moving from one area of specialization to another, but rather than an academic or professional discipline's standards we are now considering a way of living that has its own needs, ways and standards. Even so, Millgram still tends to reach for examples that relate to some kind of professional knowledge and practice. Thus he says that "to a certain kind of old-fashioned

${ }^{4}$ Millgram has previously addressed metaphysics as intellectual ergonomics in his (2009a, 217222).

${ }^{5}$ Elsewhere Millgram has explored similar arguments in print (2009b) and in an as yet unpublished work, "Refuting Skepticism with Style" (2018). 
military man" the answer to the question "Why be moral?" is that morality is honorable while to the contemporary business practitioner the answer is that it is good business practice (Millgram 2015, 226). In those different contexts, morality regulates our interactions with each other in different ways.

Chapter 6: Why Do We Think There Are Things We Ought to Do? showcases Millgram's method of cognitive-function analysis over traditional semantic analysis. The focus here is on the actionguiding character of 'ought' statements, initially on moral ought statements, but extending to ought statements more generally. The kind of basic moral statements that are considered in a variety of moral theories (moral realism, moral intuitionism, and absolutism) as just "a matter of brute, metaphysical fact" (Millgram 2015, 128) can be regarded as a simplified distillation of the outcome of more nuanced and complex reasoning. Millgram believes that the defeasibility of conclusions is a feature of practical inference more generally. For example, in means-ends inference if you desire the end then you desire the means (you want cash and the nearby ATM provides the means) but the concluding action of operating the ATM is defeasible, for "a shady character may be lurking around the site" (Millgram 2015, 132). The point is that attending to a variety of defeasibility conditions adds a significant cognitive load. To say that you ought to do something can be understood as saying there is a good argument for doing so, allowing that the full argument can involve an indefinite number of qualifications. The cognitive function of ought statements is to provide action guidance in economical form. He connects this with his thesis of hyperspecialization. We have no access to, and indeed could not comprehend, the arguments that the specialist would use to justify a recommendation. The ought statement from the specialist marks "support, while screening that support off" (Millgram 2015, 153). Again, we see how the thinking behind hyperspecialization extends beyond academic and professional disciplines.

\section{Applications to Necessity}

Let us now consider another, rather different, context to which the notion of hyperspecialization can apply. Chapter 8: Progressive Necessity addresses the question: what is the cognitive function of necessity? This is another example of how Millgram approaches metaphysics as intellectual ergonomics. ${ }^{6}$ The widespread use of modal notions in everyday and specialist context suggests

\footnotetext{
${ }^{6}$ One should also consult Millgram's (2009a) where he has outlined similar arguments in Chapter 10: "The Lewis Twist: Mind Over Matter," Chapter 11: "Bare Necessities," and Chapter 12: "Metaphysics as Intellectual Ergonomics."
} 
they play a role in our thinking, a role we should uncover. Necessities as such are unobservable and uncovering their role is made more difficult by the way modal notions present themselves to us in misleading ways. Specifically, the natural understanding of necessities is that they are unconditional and eternal but Millgram argues that necessity is progressive, for necessities are located within particular theories and mind-sets in particular domains and particular times and places. We are not speaking from some kind of notional 'end of science' perspective, à la C.S. Peirce. The claim of progressiveness is that, in general, the set of necessary truths tends to grow over time. The process of accumulating necessities is not always a smooth one, however, as branches of enquiry from time to time are abandoned as ill-founded. This will occur in Kuhnian scientific revolutions, which may require innovators to pay attention to what the established theory declares impossible ( $c f$. Kuhn 1962).

For Millgram, "necessity is a way of telling people what not to think about" (Millgram 2015, 199). A modern understanding of physics allows us to ignore patent applications for perpetual motion machines, for such things are impossible (Millgram 2015, 198). To lead into his position he describes a more primitive species, which he labels "Piltdown Man," that can adopt a specialization early in life but cannot adapt to a new specialization. A Piltdown Man is not able to even contemplate how things could have been otherwise. From that point of view, what is impossible by the tenets and standards of the specialization is not even considered. We might say those impossibilities cannot even be thought, which makes us think of the linguistic reform of "newspeak" described in George Orwell (1949), something designed to control and limit thought. Clearly this takes us on to difficult, though well-trodden, paths concerning the relationship between language and thought (See Sapir (1921) and Whorf (1956)) or indeed in the Philosophy of Science such as in Hung (2006), where languages involve category systems, which function as theories.

Let us focus, however, on Millgram's views about the function of necessity in human cognition. When a serial hyperspecializer enters a new niche, she does not know at first what to attend to and what to ignore and the necessities she learns provide that guidance. Thus the function of necessity is to serve as an attention management device. Necessities indeed can convey more generally to those outside the specialization what should be ignored. There is a question as to what function necessities play for a serial hyperspecializer currently well embedded in a particular specialization and communicating with her peers. Not being a Piltdown Man she can contemplate those necessities but they are endorsed as second nature, perhaps like the way the 
true believer in a religion can rehearse its tenets without hint of question. We can observe that hyperspecialization enters in this account of the function of necessity in a subtle and rather unexpected way.

Millgram's conception of humans as serial hyperspecializers should not lead us to think that all humans are equally versatile. Many humans are more like the notional Piltdown man than we would like to think. As automation, including forms based on artificial intelligence, invades the workforce, we find workers may be too inflexibly tied to skills that are now redundant. While a changing economy will create new jobs, which in effect require the acquisition of new specializations, not all workers are sufficiently like the idealized serial hyperspecializers to be able to adapt to them. Amongst humans, there is a spectrum of ability to move between specializations and the picture of the well-educated, multi-talented, adaptable person, which is useful for Millgram's exposition, captures one end of that spectrum. In fact, ironically, a distinguished hyperspecializer may in effect be stuck in their area of expertise. Think of Bobby Fischer who was a supreme specialist in Chess but who did not appear able to employ his extreme intelligence to achieve success in another sphere (Brady 2011).

Millgram has little time for modal logic as capturing metaphysical truths about the structure of possible worlds. As explained, he does not think that there are eternal truths about necessity but rather local practices of attention rationing. In Chapter 7, Lewis's Epicycles, Possible Worlds, and Modality, the topic is also modality, but here with an emphasis on counterfactuals, which Lewis famously handles by way of comparative similarity among worlds. In brief, "If Ann had come to the party it would have been lots of fun" is true on this approach if in the closest worlds to ours in which Ann came it was lots of fun. We are not considering those less close worlds in which, say, Ann came with Donald Trump. This chapter does not make explicit reference to hyperspecialization but it is not hard to recognize some related thinking.

According to Millgram, Lewis seeks some global ordering of similarity among worlds, but Millgram argues, plausibly, that our modal intuitions that support counterfactuals are tied to specific problem areas or topics (Millgram 2015, 179). In fact, Lewis does allow for context dependence in the interpretation of counterfactuals, which needs to be reflected in judgements of similarity among worlds (Lewis 1973; 1979: 457). Such context dependence brings us back to the thinking around specialization. Just as different specialists have different ways of 
understanding what is going on in a certain situation, so they also will arrive at different judgements as to what possible worlds are most similar to the actual one.

\section{Does Millgram's Approach Have Limitations?}

Millgram's main theme of hyperspecialization is a lens through which to regard a whole range of distinct philosophical topics, and our article is an attempt to unify these disparate stories, which is a challenge given the diversity of the areas covered. A core theme, though, is the isolation of specialist communities. There is some reason to think that specialist communities are not completely isolated, conceptually speaking. The knowledge of the quantum physicist, labelled 'subtle' by Nguyen (forthcoming) as not obviously connected with everyday experience, is understood by the semiconductor electronics specialist whose understanding in turn is familiar to the computer hardware specialist which leads to machines we are familiar with and know work, most of the time. Nguyen draws our attention to those links among scientific specializations, referring to Kitcher's (1993) notion of indirect calibration. To support or oppose that case more thoroughly would require testimony from those specialists in those linking locations. This point softens the force of the claim Millgram makes about barriers between professions and disciplines without necessarily removing the significance of the main idea.

There are attempts in scientific, engineering and policy contexts to overcome problems of intellectual isolation, by fostering interdisciplinary study and work, and the creation of interdisciplinary teams to investigate important social and technical issues. For example, Michael O'Rourke and Stephen Crowley, as well as their colleagues in the health sciences, have suggested that our philosophical training can improve communication across disciplines (Schnapp, et al., 2012; O’Rourke and Crowley 2013). Their Toolbox Project attempts to effect epistemic changes that lead to better comprehension by members of distinct scientific endeavors. That there are such attempts to remove or mitigate the kind of intellectual isolation does not automatically mean they are successful.

There is a profession that has a vested interest in the removal of intellectual isolationism. Scientists writing for a general audience, such as Stephen Hawking (1998), purport to remove the isolation not only between scientist and the non-scientist but between cosmologist and molecular biologist. Even if the author is a genuine expert and perspicuous writer, like Hawking, the truth is that even a molecular biologist may have difficulty fully comprehending Hawking's work. Hawking, like any expert, is isolated from non-experts and experts in other nearby fields. The 
merit of Millgram's claim does not depend on some artificial thesis of complete intellectual isolation, such as what may be experienced between the expert and novices. The significance of hyperspecialization can rest on a significant degree of mutual incomprehensibility amongst different specialists under the broad umbrella of science.

We have discussed Millgram's claim that humans have the capacity for being serial hyperspecializers, a capacity that is highly relevant to the modern world with its quickly changing employment market, often requiring a person to move from one specialist career to another perhaps several times during her life. What of the complementary notion of being a parallel hyperspecializer in which a person engages in different specialist interests during one period of their life? In fact, there is a place (Millgram 2015, 64-65) where Millgram discusses precisely that and later mentions presumably the same notion under the label "the synchronic disunity of agency” (Millgram 2015, 262). He speaks (Millgram 2015, 64) of a person who divides her time among being a medical journalist, an avant-garde installation artist and an owner of a country home in a small town. His point is that the standards and expectations of the three activities are incommensurable and, therefore, there is no guidance from any of those fields as to how to make tradeoffs among the demands of those three activities.

The idea of parallel hyperspecialization is powerful as it connects with important and familiar features of life in modern society but this is merely mentioned in passing in the volume. Under the heading of serial hyperspecialization, Millgram points to a kind of incommensurability between the mind-sets the person needs to adopt before and after the shift to a new specialization. Parallel hyperspecialization concerns an incommensurability between the different mind-sets associated with the specialisms contained within a single individual at the same period of life. It challenges common assumptions about the unity of the self.

We hold that there are indeed cases where different specialist mind-sets are contained within an individual at one period of life and the common embodiment does not automatically remove the incommensurability. Compare two physicists who are also golfers. For one, her knowledge of the physics of hitting golf balls and the effect of humidity, wind and other factors is well integrated into how she approaches her game. That is not to say she performs precise calculations but in making estimates she thinks in the concepts of physics. The other physicist, while on the golf course, needs to shut off his mind from his physics knowledge, at least at a technical level, and needs to think in the terms supplied by his coach. He can't translate ideas 
between the two spheres. It seems to us that the second scenario is possible, and maybe even quite common, and maybe for certain specialties is close to inevitable.

We have discussed elsewhere a thesis of the disunity of the self that echoes Millgram's thesis of segmented agency, though emphasizing parallel rather than serial hyperspecialization (Lumsden and Ulatowski 2017). Our framework was a narrative account of the self and thus our articulation of the disunity of self was that there is likely to be no overarching narrative unity to the self, either at a time or through time. Rather, there will be persisting narrative threads that bump up against each other and interact only to some extent. Leaving the narrative approach to one side, we wish to emphasize the parallel hyperspecialization thesis that is undeveloped in Millgram's volume. We consider that to be a logical next step. When we think of a specialist, we think of someone with the authority of a deep understanding of their special field. Millgram refines that picture by allowing that the specialist can change careers, which gives us serial hyperspecialization. We can move a step further and accept multiple specialisms captured simultaneously in one body, but where there is a disconnect between the two understandings. We consider that step to be an important move in bringing to the fore an important question concerning the nature of the self, that is, to what extent should we expect an overarching unity to the self, both at a time and through time?

\section{Conclusion}

In this discussion, we have critically examined Millgram's notion of hyperspecialization, including a salient form, serial hyperspecialization, which is central to The Great Endarkenment. We have shown how hyperspecialization takes different forms in different contexts and explained how this is consistent with Millgram's methodological approach. He says we should not attempt a semantic analysis of a notion but rather see how it makes reasoning about the world effective. What makes for effective reasoning will vary from situation to situation. We touched on two areas to which the notion of hyperspecialization is applied: morality and necessity. We wish to recommend these ideas as providing a useful lens through which to view a range of philosophical issues. We have noted that Millgram's central thesis of hyperspecialization need not depend on complete and total isolation between specializations. Further, we urge more attention be given to the theme of parallel hyperspecialization, where different specialisms occur concurrently in one body.

\section{Pbilosophy Programme}


University of Waikato

Private Bag 3105

Gate 1, Knighton Road

Hamilton 3240

New Zealand

david.lumsden@waikato.ac.nz.

joe.ulatowski@waikato.ac.nz.

\section{Acknowledgments}

We are grateful for the constructive feedback we received from Tracy Bowell, Fred Kroon, Elijah Millgram, Karl Pfeifer, Matheson Russell, Kathleen Wallace, and two anonymous referees, as well as a helpful conversation with Doug Campbell.

\section{References}

Brady, F. 2011. Endgame: Bobby Fischer's Remarkable Rise and Fall-from America's Brightest Prodigy to the Edge of Madness (1st ed.). New York: Crown.

Buzaglo, M. 2002. The Logic of Concept Expansion. Cambridge: Cambridge University Press.

Hawking, S. 1998. A Brief History of Time. New York: Bantam.

Hung, E. H.-C. 2006. Beyond Kubn: Scientific Explanation, Theory Structure, Incommensurability and Physical Necessity. Aldershot, UK: Ashgate.

Kitcher, P. 1993. The Advancement of Science. Oxford: Oxford University Press.

Kuhn, T. S. 1962. The Structure of Scientific Revolutions (1st ed.). Chicago: University of Chicago Press.

Lewis, D. 1973. Counterfactuals, Oxford: Blackwell Publishers and Cambridge, Mass: Harvard University Press, 1986.

1979. “Counterfactual Dependence and Time’s Arrow.” Noûs 13: 455-476. 
Lumsden, D., and J. Ulatowski. 2017. "One Self Per Customer? From Disunified Agency to Disunified Self." Southerm Journal of Philosophy 55, no.3: 314-355.

Millgram, Elijah. 2009a. Hard Truths. Oxford: Wiley-Blackwell.

-------. 2009b. "The Limits of Moral Skepticism and the Limits of Moral

Education." In The Oxford Handbook of the Philosophy of Education, edited by H. Siegel, 245-259.

Oxford: Oxford University Press.

2015. The Great Endarkenment: Philosophy for an Age of Hyperspecialization.

Oxford: Oxford University Press.

2018. "Refuting Skepticism with Style." University of Utah.

http://www.elijahmillgram.net/publications/biv.pdf. Accessed 15 January 2019.

Millikan, R. G. 2017. Beyond Concepts: Unicepts, Language, and Natural Information. Oxford:

Oxford University Press.

Nguyen, C. T. Forthcoming. "Cognitive Islands and Runaway Echo Chambers: Problems for

Epistemic Dependence on Experts." Synthese. https://doi.org/10.1007/s11229-018-1692-0.

O’Rourke, M., and S. Crowley. 2013. "Philosophical Intervention and Cross-Disciplinary

Science: the Story of the Toolbox Project.” Synthese 190, no. 11: 1937-1954.

Orwell, G. 1949. 1984. London: Secker \& Warburg.

Sapir, E. 1921. Language: An Introduction to the Study of Speech. New York: Harcourt, Brace.

Schnapp, L. M., Rotschy, L., Hall, T. E., Crowley, S., and M. O’Rourke. 2012. “How to Talk to Strangers: Facilitating Knowledge Sharing Within Translational Health Teams with the Toolbox Dialogue Method.” Translational Behavioral Medicine 2, no.4: 469-479.

Whorf, B. 1956. Carroll, John B., ed., Language, Thought, and Reality: Selected Writings of Benjamin Lee Whorf. Cambridge, Mass: The MIT Press. 
Wilson, M. 2006. Wandering Significance: An Essay on Conceptual Behavior. Oxford: Oxford University Press.

2017. Physics Avoidance: And Other Essays in Conceptual Strategy. Oxford: Oxford University Press. 